\title{
Toxic risk of stereotactic body radiotherapy and concurrent helical tomotherapy followed by erlotinib for non-small-cell lung cancer treatment - case report
}

\author{
Chen-Hsi Hsieh ${ }^{1,5^{*}}$, Hou-Tai Chang ${ }^{2}$, Shih-Chiang Lin ${ }^{3}$, Yu-Jen Chen ${ }^{5,6}$, Li-Ying Wang ${ }^{7}$, Yen-Ping Hsieh ${ }^{8}$, \\ Chien-An Chen ${ }^{1}$, Ngot-Swan Chong ${ }^{1}$, Shoei Long Lin ${ }^{9}$, Chun-Yi Chen ${ }^{10}$, Pei-Wei Shueng ${ }^{1,4^{*}}$
}

\begin{abstract}
Background: Stereotactic body radiation therapy (SBRT) applied by helical tomotherapy $(H T)$ is feasible for lung cancer in clinical. Using SBRT concurrently with erlotinib for non-small cell lung cancer (NSCLC) is not reported previously.

Case Presentation: A 77-year-old man with stage III NSCLC, received erlotinib $150 \mathrm{mg} /$ day, combined with imageguided SBRT via HT. A total tumor dose of $54 \mathrm{~Gy} / 9$ fractions was delivered to the tumor bed. The tumor responded dramatically and the combined regimen was well tolerated. After concurrent erlotinib-SBRT, erlotinib was continued as maintenance therapy. The patient developed dyspnea three months after the combined therapy and radiation pneumonitis with interstitial lung disease was suspected.

Conclusions: Combination SBRT, HT, and erlotinib therapy provided effective anti-tumor results. Nonetheless, the potential risks of enhanced adverse effects between radiation and erlotinib should be monitored closely, especially when SBRT is part of the regimen.
\end{abstract}

\section{Background}

Erlotinib, one of the epidermal growth factor receptor (EGFR) tyrosine kinase inhibitors (TKIs), is active and relatively well tolerated in chemotherapy-naïve elderly patients with advanced non-small cell lung cancer (NSCLC) [1]. Image-guided stereotactic body radiotherapy (SBRT) and helical tomotherapy (HT) using hypofractionation in patients with early-stage medically inoperable NSCLC is feasible and well tolerated [2]. For stage III NSCLC, hypofractionation yields equivalent survival rates, but without often fatal symptomatic pneumonitis, compared to conventional radiotherapy [3]. The addition of standard-dose erlotinib to chemoradiotherapy is feasible, without an increase in toxicity [4]. Little information is available on fatal pulmonary toxicity due to irradiation pneumonitis when erlotinib is

\footnotetext{
* Correspondence: chenci28@ms49.hinet.net; shueng@hotmail.com 'Department of Radiation Oncology, Far Eastern Memorial Hospital, Taipei, Taiwan

Full list of author information is available at the end of the article
}

concurrently given with SBRT and used thereafter as maintenance therapy for NSCLC.

\section{Case presentation}

A 77-year-old man was diagnosed with NSCLC, cT2N2M0, stage III A. Chest computed tomography (CT) showed a soft tissue mass measuring $4 \times 3.9 \mathrm{~cm}$ in the right upper lung, with mediastinal lymphadenopathy. Carcinoembryonic antigen (CEA) was also elevated to 12.9 $\mathrm{mg} / \mathrm{dl}$. The Patient received oral erlotinib $150 \mathrm{mg} /$ day as the first line therapy. Three months later, the CEA increased from $12.9 \mathrm{ng} / \mathrm{ml}$ to $29.1 \mathrm{ng} / \mathrm{ml}$. Then, erlotinib was added concurrently to the radiotherapy regimen. This regimen comprised 54 Gy given in nine fractions delivered with SBRT using HT, at $95 \%$ of the prescribed isodose for the planned target volume. The split courses with 3 fractions per week were prescribed. (Figure 1 and 2) Targeting was based on new, separate CT scans for each split course.

The tumor volume $(\mathrm{ml})$ vs. the right lung volume was $116.1 \mathrm{ml}$ vs. $1282.9 \mathrm{ml}$ in the first treatment course and 


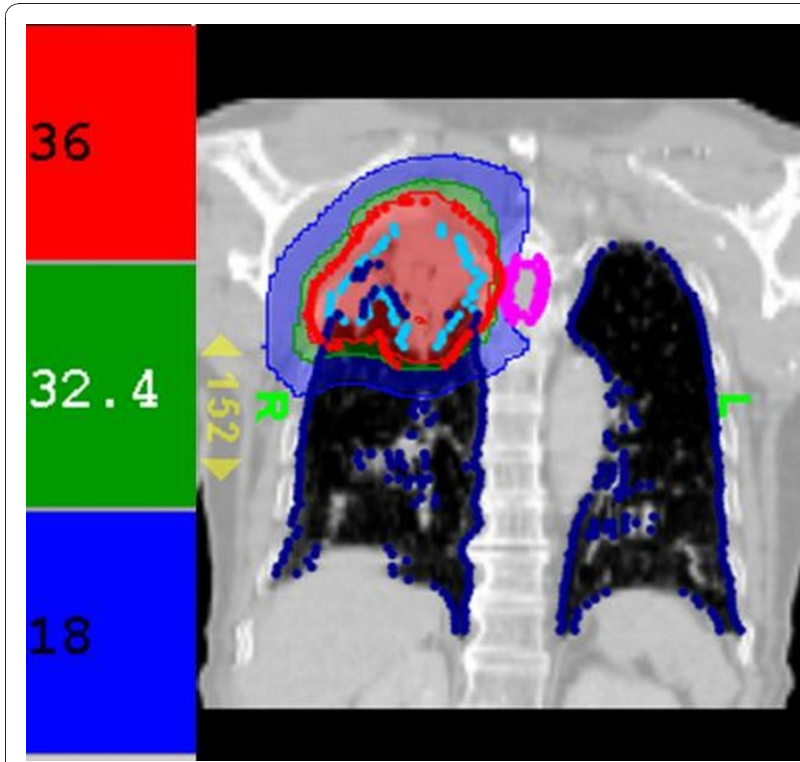

Figure 1 Dose distribution in the first treatment course Tomotherapy treatment planning with high conformity (conformal index, $\mathrm{Cl}=1.03)$. Red, green, and blue areas are $100 \%, 90 \%$, and $50 \%$ of the prescribed radiation dose, respectively. The blue dots outline the lung structure and the sky-blue dots indicate the radiation target.

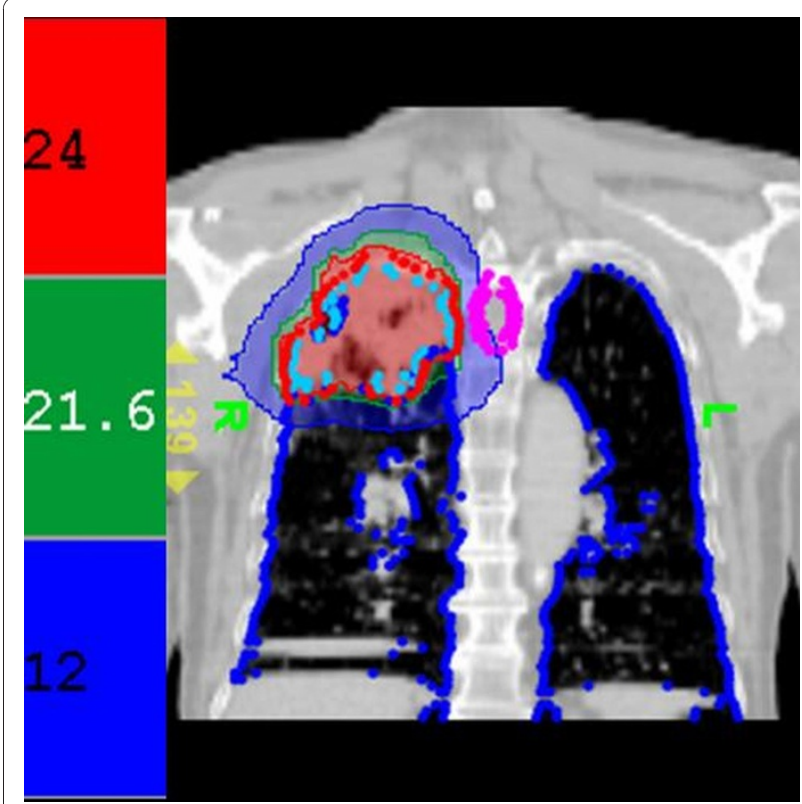

Figure 2 Dose distribution in the second treatment course. Tomotherapy treatment planning with high conformity (conformal index, $\mathrm{Cl}=1.03)$. Red, green, and blue areas are $100 \%, 90 \%$, and $50 \%$ of the prescribed radiation dose, respectively. The blue dots outline the lung structure and the sky-blue dots indicate the radiation target.
$90.9 \mathrm{ml}$ vs. $1475.9 \mathrm{ml}$ in the second treatment course. The mean lung dose, V15, and V20, where Vx was the percentage of lung volume that received at least $\times$ Gy [5] for separate lung images, is shown Table 1. The whole-course V20 and mean lung dose for the total lung were $10 \%$ and 10.24 Gy, respectively. By 2.5 months after the combination therapy, the tumor shrank from $4 \times 3.9 \times 4.5 \mathrm{~cm}$ to $2.4 \times 2.9 \times 2.1 \mathrm{~cm}$ and erlotinib $150 \mathrm{mg} /$ day was prescribed as maintenance therapy. Unfortunately, the patient developed dyspnea three months after the combination therapy. He was transferred to the medical intensive care unit. In a series of image studies, opacities of a diffuse ground-glass pattern, subpleural bleb formation in the marginal areas, airspace consolidation and fibrosis in bilateral whole lung fields were noted, and radiation pneumonitis was suspected (Figure 3, 4, 5, 6) [6,7]. The patient received empirical antibiotics, steroid therapy, antioxidant, and supportive treatment. Four more months after the combined therapy, the patient died of respiratory failure.

\section{Conclusions}

Image-guided SBRT with HT using hypofractionation in patients with early-stage medically inoperable NSCLC is feasible [2]. The hypofractionated scheme yields equivalent survival rates, without fatal, symptomatic pneumonitis for patients with stage III NSCLC when compared with conventional radiotherapy [3]. Belderbos et al. [8] reported that radiation dose escalation was safe up to 94.5 Gy in 42 fractions with a mean lung dose 13.6 Gy or less in 6 weeks in NSCLC patients. The patients underwent irradiation 5 days per week, and twice daily when more than 30 fractions were prescribed, with at least a 6-h interval in between each fraction. According to linear-quadratic (LQ) modeling [9], the biologic effect of $94.5 \mathrm{~Gy} / 42$ fractions converted to a hypofractional dose of 6 Gy per fraction (EQD6), for which the acute effects and late normal tissue effects would be equivalent to 72 and 54 Gy, respectively. The mean lung dose

Table 1 Mean lung volume, dose, V15, and V20 for each lung in the first and second radiotherapy courses, with 2 weeks interval between radiotherapy courses

\begin{tabular}{lcccc}
\hline & \multicolumn{2}{c}{ First course (0-36 Gy) } & \multicolumn{2}{c}{ Second course (36-54 Gy) } \\
\cline { 2 - 5 } & $\begin{array}{c}\text { Right lung } \\
\text { volume, } \\
\mathbf{1 1 6 7} \mathbf{~ m l}\end{array}$ & $\begin{array}{c}\text { Left lung } \\
\text { volume, } \\
\mathbf{1 2 4 4} \mathbf{~ m l}\end{array}$ & $\begin{array}{c}\text { Right lung } \\
\text { volume, } \\
\mathbf{1 3 8 5} \mathbf{~ m l}\end{array}$ & $\begin{array}{c}\text { Left lung } \\
\text { volume, } \\
\mathbf{1 4 9 0 ~} \mathbf{~ m l}\end{array}$ \\
\hline $\begin{array}{l}\text { Mean } \\
\text { lung } \\
\text { dose (Gy) }\end{array}$ & $10.77 \mathrm{~Gy}$ & $4.74 \mathrm{~Gy}$ & $4.63 \mathrm{~Gy}$ & $1.96 \mathrm{~Gy}$ \\
V15* (\%) & $27 \%$ & $2 \%$ & $13 \%$ & \\
V20* $(\%)$ & $22 \%$ & $0 \%$ & $8 \%$ & $0 \%$ \\
\hline
\end{tabular}

*V15 and V20 are the percentages of lung volume that receive at least 15 and $20 \mathrm{~Gy}$ in the ipsilateral and contralateral lungs. 


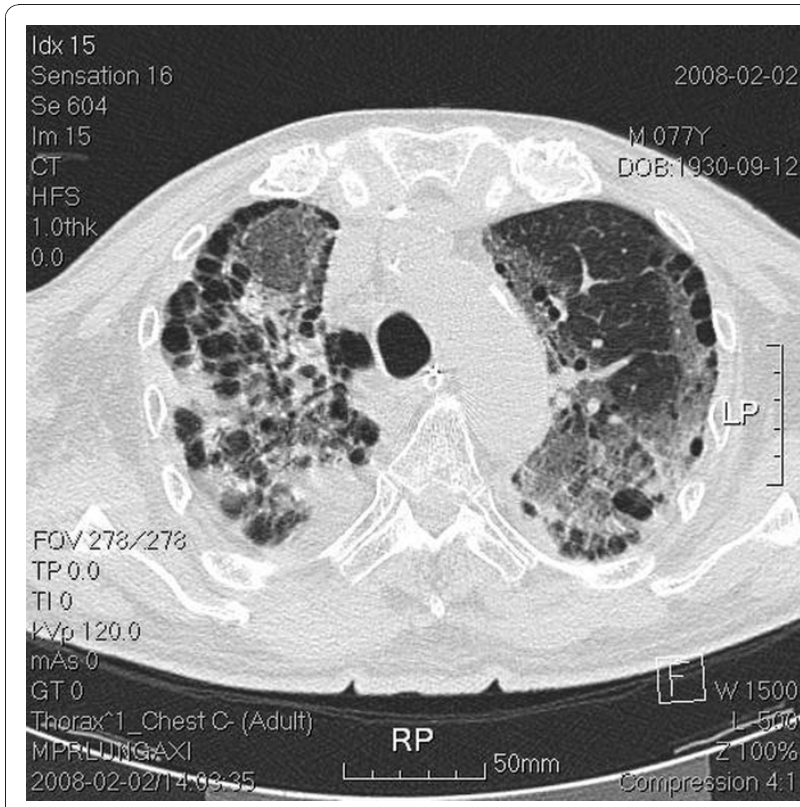

Figure 3 Transverse view of upper lung field with tumor located in the right upper lung apex. Chest computed tomography (CT) done post intubation shows ground-glass opacities, blebs confined to the right upper lung apex, and diffuse ground-glass attenuation, blebs in the marginal areas, airspace consolidation, and fibrosis in the bilateral upper and lower lung fields.

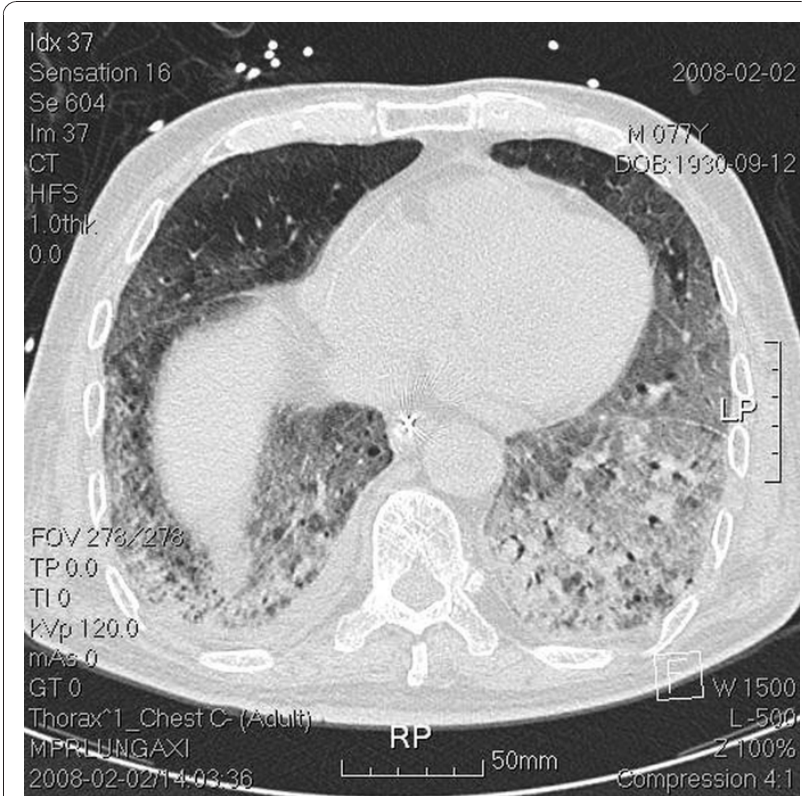

Figure 4 Transverse view of the lower lung field. Chest computed tomography (CT) done post intubation shows groundglass opacities, blebs confined to the right upper lung apex, and diffuse ground-glass attenuation, blebs in the marginal areas, airspace consolidation, and fibrosis in the bilateral upper and lower lung fields.

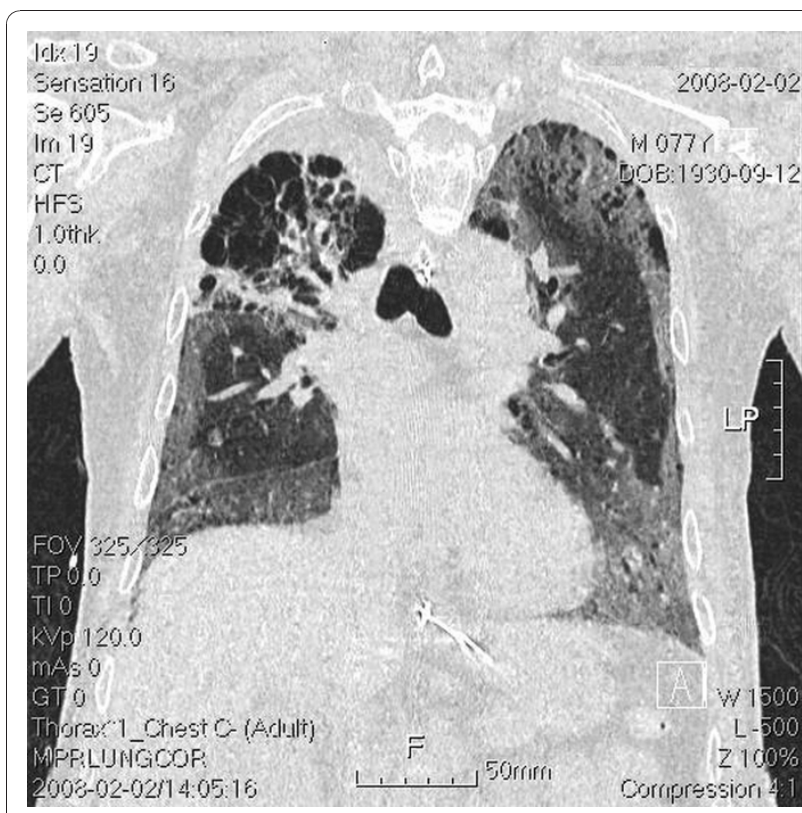

Figure 5 Coronal view of the whole lung field. Chest computed tomography $(\mathrm{CT})$ done post intubation shows ground-glass opacities, blebs confined to the right upper lung apex, and diffuse ground-glass attenuation, blebs in the marginal areas, airspace consolidation, and fibrosis in the bilateral upper and lower lung fields.

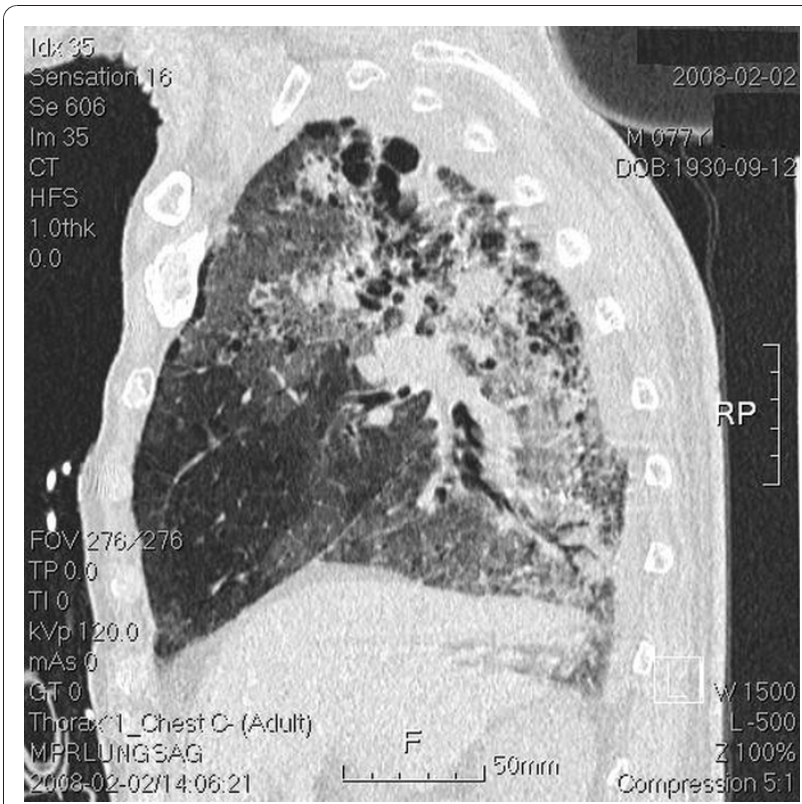

Figure 6 Sagittal view of the whole lung field. Chest computed tomography (CT) done post intubation shows ground-glass opacities, blebs confined to the right upper lung apex, and diffuse ground-glass attenuation, blebs in the marginal areas, airspace consolidation, and fibrosis in the bilateral upper and lower lung fields. 
( $\geq 21$ Gy), V20 (> 31\%) [10], and ipsilateral V20 Gy [5] correlates with radiation pneumonitis. Nonetheless, the Radiation Therapy Oncology Group 0236 protocol using SBRT via HT for NSCLC provided safe and effective treatment when the V20 was restricted to less than $10 \%$ to $15 \%$ [11]. The V15, V20, and mean lung dose for each separate lung by divided course are shown in the Table. Moreover, the whole-course V20 and mean total lung dose were $10 \%$ and 10.24 Gy, respectively. According to previous reports $[5,10,11]$, this plan was safe and no symptomatic radiation pneumonitis occurred among the NSCLC patients.

Erlotinib, an EGFR TKI, is an effective anti-tumor agent for treatment of NSCLC among elderly patients [1]. Erlotinib could be used as a single agent in select subsets of patients with advanced NSCLC [12]. In a comparative trial, only $0.8 \%$ of patients developed interstitial lung disease in the erlotinib arm [13]. Moreover, addition of standard-dose erlotinib to chemoradiotherapy was feasible and without evidence of increased toxicities [4]. However, prior tissue injury from radiation therapy could lead to cells with altered responses when the drug is subsequently applied [14]. Erlotinib enhanced radiation responses including cell cycle arrest, apoptosis induction, accelerated cellular repopulation, and DNA damage repair [15]. Therefore, it is possible for erlotinib to induce an altered response in cells when erlotinib is applied after irradiation.

Though SBRT applied by HT allows for minimization of normal tissue exposure to high radiation doses [16], the large amount of low-dose irradiation to non-target organs at risk (OAR), and thus, the incidence of lung toxicity can become high [17]. Recently, non-target OARs were impacted by arc therapy due to the low dose bath phenomenon and these effects could be magnified by agents known or unknown to be associated with recall effects [18]. Irradiation modulates the anticancer drug's pharmacokinetics even under low doses and in off-target areas [19]. Additionally, combined low-dose radiation and erlotinib induced symptomatic pneumonitis in one NSCLC patient [20]. Another NSCLC patient developed radiation recall dermatitis induced by erlotinib [21]. According to these reports, we believe EGFR inhibitor might not only enhance the effects of radiation, but also might enhance the adverse effects of radiation, especially when prescribed following previous concurrent treatment with radition. Furthermore, radiation modulates the systemic efficts of drugs regardless of the treatment effects or side effects. Erlotinib appears to modulate the effects of irradiation, both good and bad.

To our best knowledge, this is the first report of radiation pneumonitis caused by erlotinib combined with image-guided SBRT via HT with hypofractionation followed by erlotinib presecribed for maintenance.
Oncologists should be alert to the potential risk of fatal pulmonary toxicity caused by this multimodality treatment. Radiotherapy plus targeting agents must be conducted in well-designed clinical trials.

\section{Consent}

Written informed consent was obtained from the patient's family for publication of this case report and the accompanying images. A copy of the written consent is available for review by the Editor-in-Chief of the journal.

\section{Author details}

'Department of Radiation Oncology, Far Eastern Memorial Hospital, Taipei, Taiwan. ${ }^{2}$ Department of Chest Medicine, Division of Internal Medicine, Far Eastern Memorial Hospital, Taipei, Taiwan. ${ }^{3}$ Department of hematology, Far Eastern Memorial Hospital, Taipei, Taiwan. ${ }^{4}$ Department of Radiation Oncology, National Defense Medical Center, Taipei, Taiwan. ${ }^{5}$ Institutes of Traditional Medicine, School of Medicine, National Yang-Ming University, Taipei, Taiwan. ${ }^{6}$ Department of Radiation Oncology, Mackay Memorial Hospital, Taipei, Taiwan. ${ }^{7}$ School and Graduate Institute of Physical Therapy, College of Medicine, National Taiwan University, Taipei, Taiwan. ${ }^{8}$ Department of Healthcare Administration, Asia University, Taichung, Taiwan. ${ }^{9}$ Department of Surgery, Taipei Hospital, Department of Health, Taipei, Taiwan. ${ }^{10}$ Division of Medical Oncology, Department of Internal Medicine, Taipei Hospital, Department of Health, Taipei, Taiwan.

\section{Authors' contributions}

$\mathrm{CHH}$ and PWS perfromed all $\mathrm{CT}$ evaluations, designed the study, made the target delineations, and interpreted the study results. $\mathrm{CHH}$ drafted the manuscript. SCL, CAC, SLL, CYC and HTC care for the patient. YJC, LYW, and YPH advised on all aspects of the work. NSC participated in radiation plannning. All authors read and approved the final manuscript.

\section{Competing interests}

The authors declare that they have no competing interests.

Received: 2 June 2010 Accepted: 31 December 2010

Published: 31 December 2010

\section{References}

1. Jackman DM, Yeap BY, Lindeman NI, Fidias P, Rabin MS, Temel J, Skarin AT, Meyerson M, Holmes AJ, Borras AM, et al: Phase II clinical trial of chemotherapy-naive patients $>$ or $=70$ years of age treated with erlotinib for advanced non-small-cell lung cancer. J Clin Oncol 2007 25(7):760-766

2. Hodge W, Tome WA, Jaradat HA, Orton NP, Khuntia D, Traynor A, Weigel T, Mehta MP: Feasibility report of image guided stereotactic body radiotherapy (IG-SBRT) with tomotherapy for early stage medically inoperable lung cancer using extreme hypofractionation. Acta Oncol 2006, 45(7):890-896.

3. Slotman BJ, Njo KH, de Jonge A, Meijer OW, Karim AB: Hypofractionated radiation therapy in unresectable stage III non-small cell lung cancer. Cancer 1993, 72(6):1885-1893.

4. Choong NW, Mauer AM, Haraf DJ, Lester E, Hoffman PC, Kozloff M, Lin S, Dancey JE, Szeto L, Grushko T, et al: Phase I trial of erlotinib-based multimodality therapy for inoperable stage III non-small cell lung cancer. J Thorac Oncol 2008, 3(9):1003-1011.

5. Yorke ED, Jackson A, Rosenzweig KE, Merrick SA, Gabrys D, Venkatraman ES, Burman CM, Leibel SA, Ling CC: Dose-volume factors contributing to the incidence of radiation pneumonitis in non-small-cell lung cancer patients treated with three-dimensional conformal radiation therapy. Int J Radiat Oncol Biol Phys 2002, 54(2):329-339.

6. Choi YW, Munden RF, Erasmus JJ, Park KJ, Chung WK, Jeon SC, Park CK: Effects of radiation therapy on the lung: radiologic appearances and differential diagnosis. Radiographics 2004, 24(4):985-997, discussion 998. 
7. Liu V, White DA, Zakowski MF, Travis W, Kris MG, Ginsberg MS, Miller VA, Azzoli CG: Pulmonary toxicity associated with erlotinib. Chest 2007, 132(3):1042-1044.

8. Belderbos JS, Heemsbergen WD, De Jaeger K, Baas P, Lebesque JV: Final results of a Phase $1 /$ /I dose escalation trial in non-small-cell lung cancer using three-dimensional conformal radiotherapy. Int I Radiat Oncol Biol Phys 2006, 66(1):126-134

9. Fowler JF: The first James Kirk memorial lecture. What next in fractionated radiotherapy? Br J Cancer Suppl 1984, 6:285-300.

10. Graham MV, Purdy JA, Emami B, Harms W, Bosch W, Lockett MA, Perez CA Clinical dose-volume histogram analysis for pneumonitis after $3 D$ treatment for non-small cell lung cancer (NSCLC). Int I Radiat Oncol Biol Phys 1999, 45(2):323-329.

11. Baisden JM, Romney DA, Reish AG, Cai J, Sheng K, Jones DR, Benedict SH, Read PW, Larner JM: Dose as a function of lung volume and planned treatment volume in helical tomotherapy intensity-modulated radiation therapy-based stereotactic body radiation therapy for small lung tumors. Int J Radiat Oncol Biol Phys 2007, 68(4):1229-1237.

12. Carrion RP, Gracian AC, Hernandez PS: Erlotinib as a single agent in select subsets of patients with advanced non-small-cell lung cancer. Clin Lung Cancer 2007, 8(7):425-428.

13. Herbst RS, Prager D, Hermann R, Fehrenbacher L, Johnson BE, Sandler A, Kris MG, Tran HT, Klein P, Li X, et al: TRIBUTE: a phase III trial of erlotinib hydrochloride (OSI-774) combined with carboplatin and paclitaxel chemotherapy in advanced non-small-cell lung cancer. J Clin Oncol 2005, 23(25):5892-5899.

14. Kitani H, Kosaka T, Fujihara T, Lindquist K, Elkind MM: The "recall effect" in radiotherapy: is subeffective, reparable damage involved? Int I Radiat Oncol Biol Phys 1990, 18(3):689-695.

15. Chinnaiyan $P$, Huang $S$, Vallabhaneni $G$, Armstrong E, Varambally $S$, Tomlins SA, Chinnaiyan AM, Harari PM: Mechanisms of enhanced radiation response following epidermal growth factor receptor signaling inhibition by erlotinib (Tarceva). Cancer Res 2005, 65(8):3328-3335.

16. Milano MT, Constine LS, Okunieff P: Normal tissue toxicity after small field hypofractionated stereotactic body radiation. Radiat Oncol 2008, 3:36.

17. Yamashita H, Nakagawa K, Nakamura N, Koyanagi H, Tago M, Igaki H, Shiraishi K, Sasano N, Ohtomo K: Exceptionally high incidence of symptomatic grade 2-5 radiation pneumonitis after stereotactic radiation therapy for lung tumors. Radiat Oncol 2007, 2:21.

18. Shueng PW, Lin SC, Chang HT, Chong NS, Chen YJ, Wang LY, Hsieh YP, Hsieh CH: Toxicity risk of non-target organs at risk receiving low-dose radiation: case report. Radiat Oncol 2009, 4:71.

19. Hsieh CH, Hsieh YJ, Liu CY, Tai HC, Huang YC, Shueng PW, Wu L, Wang LY, Tsai TH, Chen YJ: Abdominal irradiation modulates 5-Fluorouracil pharmacokinetics. J Transl Med 2010, 8:29.

20. Nanda A, Dias-Santagata DC, Stubbs H, O'Hara CJ, Zaner KS, Lynch TJ, Willers $\mathrm{H}$ : Unusual tumor response and toxicity from radiation and concurrent erlotinib for non-small-cell lung cancer. Clin Lung Cancer 2008, 9(5):285-287.

21. Dauendorffer JN, Dupuy A: Radiation recall dermatitis induced by erlotinib. J Am Acad Dermatol 2009, 61(6):1086.

\section{Pre-publication history}

The pre-publication history for this paper can be accessed here: http://www.biomedcentral.com/1471-2407/10/696/prepub

\section{doi:10.1186/1471-2407-10-696}

Cite this article as: Hsieh et al:: Toxic risk of stereotactic body radiotherapy and concurrent helical tomotherapy followed by erlotinib for non-small-cell lung cancer treatment - case report. BMC Cancer 2010 10:696.

\section{Submit your next manuscript to BioMed Central and take full advantage of:}

- Convenient online submission

- Thorough peer review

- No space constraints or color figure charges

- Immediate publication on acceptance

- Inclusion in PubMed, CAS, Scopus and Google Scholar

- Research which is freely available for redistribution

Submit your manuscript at www.biomedcentral.com/submit
Biomed Central 